\title{
Maternal coffee intake and the risk of bleeding in early pregnancy: a cross- sectional analysis
}

\author{
Hansol Choi ${ }^{1}$, Seul Koo ${ }^{1}$ and Hyun-Young Park ${ }^{2^{*}}$ (D)
}

\begin{abstract}
Background: Caffeine can easily cross the placenta, and maternal caffeine intake, thus, has an effect on fetal growth. However, it is still unclear whether coffee consumption is an independent risk factor for bleeding in early pregnancy. The objective of this study was to examine the association between pre-pregnancy coffee consumption patterns and the risk of bleeding in early pregnancy.

Methods: A cross-sectional analysis was conducted among 3510 pregnant women from the Korean Pregnancy Outcome Study who underwent baseline examination and for whom the results of the pregnancy were available. Coffee consumption patterns before pregnancy were examined using a questionnaire. The participants were classified according to the frequency of coffee consumption into seldom ( $<1$ cup/week), light ( $<1$ cup/day), moderate ( 1 cup/day), and heavy coffee drinker ( $\geq 2$ cups/day) groups. Bleeding in early pregnancy was defined as the occurrence of vaginal bleeding in the first 20 weeks of pregnancy. Multiple logistic regression models were applied to examine the association between pre-pregnancy coffee consumption and the risk of bleeding in early pregnancy, after adjusting for age, body mass index (BMI), systolic blood pressure, cigarette smoking and alcohol consumption behavior, previous and current physical activity levels, stress levels, history of depression, antenatal depressive symptoms during the first trimester, type of emesis, parity, and the number of livebirths, stillbirths, miscarriages, and abortions.
\end{abstract}

Results: Women who were light, moderate, and heavy coffee drinkers before pregnancy had adjusted ORs of 1.086, 1.225 , and 1.358, respectively, for bleeding in early pregnancy. In a fully adjusted model, heavy coffee drinkers showed a significantly higher risk of bleeding in early pregnancy, even in women aged 35 years and younger (OR 1.680) and in those with a normal body mass index (OR 1.389), who were at relatively low risk for pregnancy-related complications.

Conclusions: Our results showed that heavy coffee drinking was independently associated with a higher risk of bleeding in early pregnancy among pregnant Korean women, suggesting that caffeine intake before conception and during pregnancy should be reduced. Our study highlights the need for nutritional interventions for healthy coffee drinking among pregnant women in Korea.

Keywords: Caffeine, Coffee consumption, Fetus, Placenta, Pregnancy

\footnotetext{
* Correspondence: mdhypark@gmail.com

${ }^{2}$ Center for Genome Science, Korea National Institute of Health, Korea

Centers for Disease Control \& Prevention, Cheongju, Republic of Korea

Full list of author information is available at the end of the article
}

(c) The Author(s). 2020 Open Access This article is distributed under the terms of the Creative Commons Attribution 4.0 International License (http://creativecommons.org/licenses/by/4.0/), which permits unrestricted use, distribution, and reproduction in any medium, provided you give appropriate credit to the original author(s) and the source, provide a link to the Creative Commons license, and indicate if changes were made. The Creative Commons Public Domain Dedication waiver (http://creativecommons.org/publicdomain/zero/1.0/) applies to the data made available in this article, unless otherwise stated. 


\section{Background}

Coffee is one of the most popular beverages worldwide [1-3]. The Korean National Health and Nutrition Examination Survey reported that the prevalence of daily coffee drinking (1 or more cups/day) greatly increased from $54.6 \%$ in 2001 to $65.3 \%$ in $2010-2011$ among Korean adults [4]. The average coffee consumption among Korean adults is 11.3 times/week - more than five times greater than that in other countries in the Asia-Pacific region [3]. Coffee contains several physiologically active substances; caffeine, in particular, is an important component of coffee $[5,6]$. Other caffeinated beverages or foods do not contribute significantly to the daily caffeine intake among Koreans [7]. Therefore, it is important to examine the effect of coffee consumption on health.

Interestingly, among all the dietary ingredients with a potential to adversely affect fetoplacental development, caffeine is the most commonly consumed by pregnant women. Maternal caffeine intake during pregnancy affects fetal growth because caffeine can easily cross the placenta and decrease blood flow to the placenta $[8,9]$. There are ongoing concerns that coffee intake could increase among pregnant women in particular and result in adverse health effects. However, the specific effects of caffeine on the fetus remain unknown. Moreover, it is still unclear whether coffee consumption is an independent risk factor for bleeding in early pregnancy, which is the most common complication of pregnancy (noted in $15-20 \%$ of all ongoing pregnancies) $[10,11]$ and may indicate underlying placental dysfunction that could induce complications in later phases of pregnancy [12, 13].

Therefore, the aim of this study was to examine prepregnancy coffee consumption patterns and their association with the risk of bleeding in early pregnancy among pregnant Korean women.

\section{Methods}

\section{Study participants}

Data for the present study were derived from the Korean Pregnancy Outcome Study (KPOS), a prospective cohort study. Between March 2013 and January 2017, all pregnant women who visited Cheil General Hospital and CHA Hospital for antenatal care during the first trimester were asked to participate in the KPOS. Women were excluded from enrolment if they were not Korean or were pregnant with triplets or higher-order multiple gestations. Gestational age was determined based on the date of the last menstrual period in women who had conceived naturally, and was confirmed by the first trimester ultrasound. After the first antenatal visit, eligible participants were requested to complete several sets of questionnaires or examinations at each of the following visits: visit 1 in the first trimester (around 12 weeks of gestation); visit 2 in the second trimester (around 24 weeks of gestation); visit 3 in the third trimester (around 36 weeks of gestation); visit 4 at birth; and visit 5 at 4-6 weeks after birth.

As shown in Supplementary Fig. 1 [see Additional file 1], after excluding 55 individuals with missing dietary data, we performed a cross-sectional analysis of 3510 women who had positive pregnancy results. Trained research nurses explained the study in detail, obtained written informed consents, and completed questionnaires. All participants provided written informed consent, and the study protocol was approved by the Institutional Review Board (IRB) of Cheil General Hospital (IRB number: CGH-IRB-2013-10) and CHA University Gangnam CHA Hospital IRB (IRB number: 2013-14-KNC13-018), separately. It was clearly explained to all participants that they were free to withdraw from any part of the study at any point in time.

\section{Measurements}

A face-to-face interview was conducted to evaluate participants' socio-demographic profiles, medical and family history, reproductive information, health-related behaviors, and psychological health. Data on sociodemographic status included age, educational level, household income, employment status, marital status, cohabiting family composition, and information on spouses. Family history of hypertension, diabetes, gestational diabetes mellitus, preeclampsia, depression, and other mental illness was also taken. The questionnaires which we used in this study was uploaded as Supplementary File 1.

Participants underwent clinical and laboratory examinations, including anthropometric measurements, blood pressure measurements, and blood and urine laboratory tests during pregnancy. Asian classifications of obesity were made in this study using the body mass index (BMI) [13]. Symptoms of depression were assessed using the Korean version of the Edinburgh Postnatal Depression Scale (K-EPDS), which is a reliable measurement for peripartum depression and validated questionnaire with 10 items; those with K-EPDS scores $\geq 10$ were considered to have symptoms of antenatal depression [14, 15]. Those taking anti-depressant drugs and those with a self-reported physician's diagnosis of depression were considered to have a history of depression. Cigarette smoking, alcohol intake, and supplement intake were evaluated during each visit. Physical activity was assessed during each visit with a self-reported questionnaire.

Dietary intake patterns were evaluated using a questionnaire during the first visit. The coffee consumption pattern before conception was determined through the question, "How often did you drink coffee before the pregnancy?" on the questionnaire. Coffee consumption was categorized into five groups (seldom, 2-3 cups/ 
week, 4-6 cups/week, 1 cup/day, and 2 or more cups/ day). In the analysis, participants were divided into four groups based on their reported amount of coffee consumption: $\geq 2$ cups/day, "heavy coffee drinkers"; 1 cup/ day, "moderate coffee drinkers"; < 1 cup/day, "light coffee drinkers"; and < 1 cup/week, "seldom coffee drinkers" (reference group). Preferences for the following types of coffee were noted: black coffee, black coffee with sugar, black coffee with creamer, and instant coffee mix (instant coffee with creamer and sugar).

We obtained information on antenatal pregnancy complications and birth details. First trimester complications, including emesis and bleeding in early pregnancy, were assessed during the first visit. In this study, bleeding in early pregnancy was defined as the occurrence of vaginal bleeding of a closed cervix in the first 20 weeks of pregnancy, confirmed using ultrasonographic examinations by a physician [16, 17]. The birth outcomes included gestational age at birth, type of labor (induced or spontaneous), type of birth, indication for Caesarean birth, and birth complications.

Blood pressure was measured during every visit using the automatic oscillometric technique, but a diagnosis of hypertensive disorders of pregnancy was confirmed by manual measurements using blood pressure cuffs and auscultation. Blood samples and placenta were stored in $70{ }^{\circ} \mathrm{C}$ freezers at a controlled temperature and humidity. All biological samples were marked with barcodes and stored in the National Biobank of Korea. We uploaded the data from all questionnaires and examinations to a webbased clinical data management system (iCReaT) managed by the Korea National Institute of Health.

\section{Statistical analysis}

We summarized the general characteristics of study participants using means and standard deviations for continuous variables and observed numbers and percentages for categorical variables. To statistically analyze differences among groups, a general linear model and the chisquare test were used for continuous and categorical variables, respectively. The Bonferroni post-hoc test was used to identify groups showing significant differences and the results are shown in Supplementary Fig. 2. For some analyses, the lower categories of exposure variables were combined into a single stratum because of the small number of subjects in these categories. Multivariate logistic regression analysis was used to estimate odds ratios (ORs) with 95\% confidence intervals (CIs) for the association between coffee consumption and bleeding in early pregnancy. Age, BMI, systolic blood pressure, cigarette smoking and alcohol consumption behavior, previous and current physical activity levels, stress levels, history of depression, presence of antenatal depressive symptom during the first trimester, type of emesis, parity, and the number of livebirths, stillbirths, miscarriages, and abortions were considered as covariates in the adjusted model.

An additional sensitivity analysis was performed with stratification according to age and BMI. We also performed an additional multiple logistic regression analysis to estimate the association between the type of coffee preferred and the risk of bleeding in early pregnancy. All statistical analyses were performed using the SAS software (version 9.4, SAS; NC, USA), and two-sided $p$ values less than 0.05 were considered indicators of statistical significance.

\section{Results}

Table 1 presents the baseline characteristics of all study participants according to the frequency of coffee consumption before pregnancy. Of the 3510 participants, 1077 were seldom coffee drinkers (30.7\%), 595 were light coffee drinkers (17.0\%), 1202 were moderate coffee drinkers (34.2\%), and 636 were heavy coffee drinkers (18.1\%). The mean age of all pregnant women was 33.3 years. Heavy coffee drinkers were more likely to be significantly older; have a higher economic status, BMI, and frequency of history of depression; and be former smokers and drinkers. The overall prevalence of bleeding in early pregnancy among these pregnant women was 18.1\%. As shown in Supplementary Table 1, a total of 46 miscarriages or abortions occurred; however, it was not significantly different according to coffee consumption. As shown in Fig. 1, heavy coffee drinkers showed the highest prevalence of bleeding in early pregnancy; this group, in particular, tended to require drug therapy or inpatient treatment for bleeding in early pregnancy.

Age- and BMI-dependent adjusted ORs for bleeding in early pregnancy in the different coffee consumption groups are presented in Tables 2 and 3, respectively. The group with the highest coffee consumption showed a high risk of bleeding in early pregnancy, and this association was significant both before and after additional adjustment for covariates. As shown in Fig. 2, heavy coffee drinkers showed a significantly higher prevalence of bleeding in early pregnancy than did seldom coffee drinkers. Light, moderate, and heavy coffee drinkers showed adjusted ORs of 1.086, 1.225, and 1.358, respectively, for bleeding in early pregnancy. This association was significant in all age groups, except for in women older than 35-40 years, who are already at risk of pregnancy complications (Table 2 and Supplementary Table 2) (see Additional file 1).

Regarding BMI, a higher consumption of coffee was significantly associated with the risk of bleeding in early pregnancy in women with normal BMI (Table 3). However, this association was not statistically significant in overweight or obese pregnant women. 
Table 1 Baseline characteristics of study participants $(n=3510)$

\begin{tabular}{|c|c|c|c|c|c|}
\hline \multirow[t]{2}{*}{ Variables } & \multicolumn{4}{|c|}{ Frequency of coffee consumption } & \multirow[t]{2}{*}{$p$-value } \\
\hline & $\begin{array}{l}\text { Seldom coffee } \\
\text { drinkers }(n=1077)\end{array}$ & $\begin{array}{l}\text { Light coffee drinkers }(<1 \\
\text { cup/day) }(n=595)\end{array}$ & $\begin{array}{l}\text { Moderate coffee drinkers (1 } \\
\text { cup/day) }(n=1202)\end{array}$ & $\begin{array}{l}\text { Heavy coffee drinkers }(\geq 2 \\
\text { cups/day) }(n=636)\end{array}$ & \\
\hline Maternal age, years & $32.8 \pm 3.8$ & $33.1 \pm 3.8$ & $33.4 \pm 3.6$ & $34.1 \pm 3.8$ & $<0.001$ \\
\hline $20-24$ & $11(1.0)$ & $7(1.2)$ & $5(0.4)$ & $1(0.2)$ & $<0.001$ \\
\hline $25-29$ & 203(18.8) & $99(16.6)$ & 184(15.3) & $62(9.7)$ & \\
\hline $30-34$ & $515(47.8)$ & 277(46.6) & $558(46.4)$ & 292(45.9) & \\
\hline $35-39$ & $303(28.1)$ & 185(31.1) & 392(32.6) & 220(34.6) & \\
\hline$\geq 40$ & $45(4.2)$ & $27(4.5)$ & $63(5.2)$ & $61(9.6)$ & \\
\hline \multicolumn{6}{|l|}{ Marital status } \\
\hline Married & 1055(98.0) & $581(97.6)$ & 1184(98.5) & $620(97.5)$ & 0.446 \\
\hline Unmarried & $22(2.0)$ & $13(2.2)$ & $18(1.5)$ & $15(2.4)$ & \\
\hline $\begin{array}{l}\text { Divorced/ Widowed/ } \\
\text { Separated }\end{array}$ & $0(0.0)$ & $1(0.2)$ & $0(0.0)$ & $1(0.2)$ & \\
\hline \multicolumn{6}{|l|}{ Educational status } \\
\hline$\leq$ High school & $92(8.5)$ & $54(9.1)$ & $83(6.9)$ & $64(10.1)$ & 0.075 \\
\hline College or university & $810(75.2)$ & $442(74.3)$ & 923(76.8) & $447(70.3)$ & \\
\hline$\geq$ Graduate school & $175(16.2)$ & $99(16.6)$ & 196(16.3) & $125(19.7)$ & \\
\hline $\begin{array}{l}\text { Systolic blood pressure, } \\
\mathrm{mmHg}\end{array}$ & $113.1 \pm 13.1$ & $114.6 \pm 14.1$ & $114.1 \pm 13.3$ & $114.6 \pm 13.0$ & 0.068 \\
\hline $\mathrm{BMl}, \mathrm{kg} / \mathrm{m}^{2 *}$ & $21.3 \pm 3.1$ & $21.8 \pm 3.2$ & $21.7 \pm 3.0$ & $22.2 \pm 3.1$ & $<0.001$ \\
\hline$<18.5$ & 155(14.4) & $52(8.7)$ & $116(9.7)$ & $50(7.9)$ & $<0.001$ \\
\hline $18.5-22.9$ & $677(62.9)$ & $379(63.7)$ & $772(64.2)$ & 379(59.6) & \\
\hline $23.0-24.9$ & 134(12.4) & $81(13.6)$ & 157(13.1) & 104(16.4) & \\
\hline $25.0-29.9$ & $91(8.4)$ & $67(11.3)$ & 137(11.4) & $86(13.5)$ & \\
\hline$\geq 30.0$ & 20(1.9) & $16(2.7)$ & $20(1.7)$ & $17(2.7)$ & \\
\hline Emesis & $801(74.4)$ & $447(75.1)$ & $942(78.4)$ & 497(78.1) & 0.085 \\
\hline Bleeding in early pregnancy & $173(16.1)$ & 103(17.3) & 226(18.8) & 134(21.1) & 0.059 \\
\hline Stabilization & 130(75.1) & $80(77.7)$ & 172(76.1) & $98(73.1)$ & 0.987 \\
\hline Drug treatment & $34(19.7)$ & 19(18.4) & $42(18.6)$ & 29(21.6) & \\
\hline Inpatient treatment & $9(5.2)$ & $4(3.9)$ & $12(5.3)$ & $7(5.2)$ & \\
\hline \multicolumn{6}{|l|}{ Number of fetus } \\
\hline Singleton & $1061(98.5)$ & $584(98.2)$ & 1188(98.8) & 623(98.0) & 0.461 \\
\hline Twin & $16(1.5)$ & $11(1.8)$ & $14(1.2)$ & $13(2.0)$ & \\
\hline Parity & $0.4 \pm 0.6$ & $0.5 \pm 0.6$ & $0.5 \pm 0.6$ & $0.4 \pm 0.6$ & 0.005 \\
\hline 0 & $677(62.9)$ & $341(57.3)$ & $681(56.7)$ & $399(62.7)$ & 0.001 \\
\hline 1 & $362(33.6)$ & $223(37.5)$ & $454(37.8)$ & 192(30.2) & \\
\hline$\geq 2$ & $38(3.5)$ & $31(5.2)$ & $67(5.6)$ & $45(7.1)$ & \\
\hline History of depression & $5(0.5)$ & $3(0.5)$ & $8(0.7)$ & $5(0.8)$ & 0.037 \\
\hline $\begin{array}{l}\text { Antenatal depressive } \\
\text { symptoms }\end{array}$ & 194(18.0) & 113(19.0) & $217(18.1)$ & $141(22.2)$ & 0.136 \\
\hline \multicolumn{6}{|l|}{ Type of coffee $(n=2394)$} \\
\hline Black coffee & & $355(60.4)$ & $781(65.9)$ & $402(64.7)$ & $<0.001$ \\
\hline Black coffee with sugar & & $50(8.5)$ & $96(8.1)$ & $23(3.7)$ & \\
\hline $\begin{array}{l}\text { Black coffee with non-dairy } \\
\text { creamer }\end{array}$ & & $28(4.8)$ & $47(4.0)$ & $15(2.4)$ & \\
\hline Instant coffee with sugar & & $155(26.4)$ & $261(22.0)$ & $181(29.1)$ & \\
\hline
\end{tabular}


Table 1 Baseline characteristics of study participants $(n=3510)$ (Continued)

\begin{tabular}{|c|c|c|c|c|c|}
\hline \multirow[t]{2}{*}{ Variables } & \multicolumn{4}{|c|}{ Frequency of coffee consumption } & \multirow[t]{2}{*}{$p$-value } \\
\hline & $\begin{array}{l}\text { Seldom coffee } \\
\text { drinkers }(n=1077)\end{array}$ & $\begin{array}{l}\text { Light coffee drinkers }(<1 \\
\text { cup/day) }(n=595)\end{array}$ & $\begin{array}{l}\text { Moderate coffee drinkers ( } 1 \\
\text { cup/day) }(n=1202)\end{array}$ & $\begin{array}{l}\text { Heavy coffee drinkers ( } \geq 2 \\
\text { cups/day) }(n=636)\end{array}$ & \\
\hline \multicolumn{6}{|c|}{ and non-dairy creamer } \\
\hline \multicolumn{6}{|l|}{ Cigarette smoking } \\
\hline Never smoked & 970(90.1) & $546(91.8)$ & $1081(89.9)$ & $538(84.6)$ & \multirow[t]{3}{*}{$<0.001$} \\
\hline Former smoker & 107(9.9) & $47(7.9)$ & 121(10.1) & $96(15.1)$ & \\
\hline Current smoker & $0(0.0)$ & $2(0.3)$ & $0(0.0)$ & $2(0.3)$ & \\
\hline \multicolumn{6}{|l|}{ Alcohol consumption } \\
\hline Never drank & $245(22.7)$ & $129(21.7)$ & 193(16.1) & $98(15.4)$ & \multirow[t]{3}{*}{$<0.001$} \\
\hline Former drinker & $830(77.1)$ & $465(78.2)$ & 1009(83.9) & $537(84.4)$ & \\
\hline Current drinker & $2(0.2)$ & $1(0.2)$ & $0(0.0)$ & $1(0.2)$ & \\
\hline \multicolumn{6}{|c|}{ Physical activity ( $n=3459$ ) } \\
\hline Static activity & 265(24.9) & $132(22.5)$ & 259(21.9) & 136(21.8) & \multirow[t]{4}{*}{$<0.001$} \\
\hline Light activity & $551(51.8)$ & $352(60.0)$ & $693(58.5)$ & $387(61.9)$ & \\
\hline Moderate activity & $246(23.1)$ & $103(17.5)$ & 232(19.6) & $100(16.0)$ & \\
\hline$\leq$ Vigorous activity & $1(0.1)$ & $0(0.0)$ & $0(0.0)$ & $2(0.3)$ & \\
\hline
\end{tabular}

Data expressed as mean \pm standard deviation or number (percentage)

*Asian classification of obesity used in this study

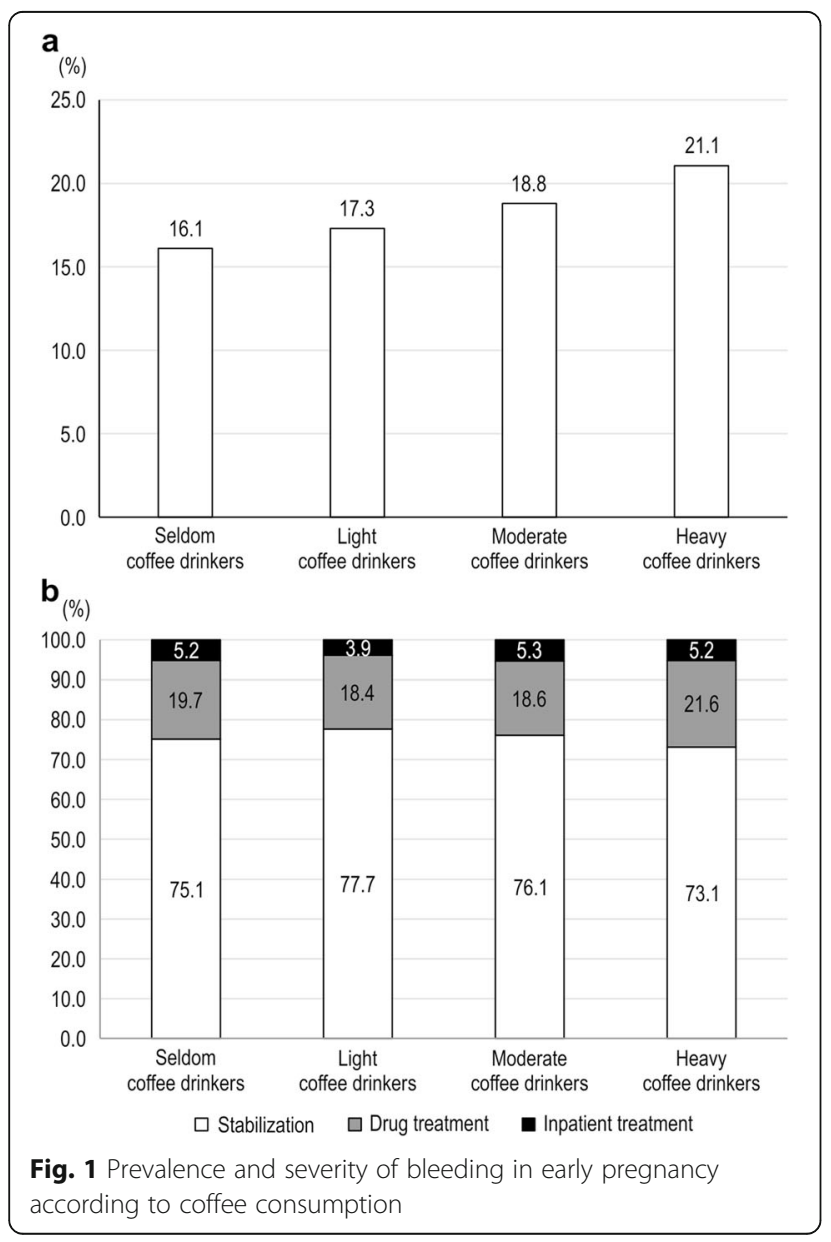

As shown in Supplementary Table 3 [see Additional file 1], no significant associations were observed between the type of coffee, additives, and the risk of bleeding in early pregnancy.

\section{Discussion}

As younger women continue to partake in the western coffee culture and demand high-quality coffee beans, the current trends of coffee consumption are expected to continue. The properties of coffee make it a doubleedged sword, and the balance between its beneficial and harmful health impacts should be considered. In this study, we examined coffee consumption patterns before pregnancy and their association with the risk of bleeding in early pregnancy among pregnant Korean women. Our study showed that women who were habitual coffee drinkers before pregnancy constituted a larger fraction of those experiencing bleeding in early pregnancy than women who were seldom coffee drinkers. We found that habitual coffee consumption of one or more cup/day before pregnancy was significantly associated with an increased risk of bleeding in early pregnancy, even after adjustment for cigarette smoking and alcohol consumption. However, the type of coffee consumed did not significantly affect the risk of bleeding in early pregnancy.

In the present study, among 3510 pregnant women, the overall prevalence of bleeding in early pregnancy was $18.1 \%$, even though the average maternal age of participants was relatively high, which is consistent with previous results. Bleeding in early pregnancy is associated with an 
Table 2 Association between coffee consumption frequency and the risk of bleeding in early pregnancy according to age $(\mathrm{n}=$ 3510)

\begin{tabular}{|c|c|c|c|c|}
\hline & Total No. & No. (\%) & Unadjusted OR (95\% Cl) & Adjusted OR $(95 \% \mathrm{Cl})^{\mathrm{a}}$ \\
\hline Overall & 3510 & $636(18.1)$ & & \\
\hline Seldom coffee drinkers & 1077 & 173(16.1) & 1.000 & 1.000 \\
\hline Light coffee drinkers (< 1 cup/day) & 595 & 103(17.3) & 1.094(0.837-1.429) & $1.086(0.827-1.425)$ \\
\hline Moderate coffee drinkers (1 cup/day) & 1202 & $226(18.8)$ & $1.210(0.973-1.504)$ & $1.225(0.981-1.530)$ \\
\hline Heavy coffee drinkers ( $\geq 2$ cups/day) & 636 & $134(21.1)$ & $1.395(1.086-1.792)$ & $1.358(1.050-1.757)$ \\
\hline Aged $<35$ years & 2214 & $372(16.8)$ & & \\
\hline Seldom coffee drinkers & 729 & $111(15.2)$ & 1.000 & 1.000 \\
\hline Light coffee drinkers (< 1 cup/day) & 383 & $57(14.9)$ & $0.973(0.688-1.376)$ & 0.993(0.699-1.411) \\
\hline Moderate coffee drinkers (1 cup/day) & 747 & $125(16.7)$ & $1.119(0.847-1.479)$ & $1.163(0.875-1.547)$ \\
\hline Heavy coffee drinkers ( $\geq 2$ cups/day) & 355 & $79(22.3)$ & $1.594(1.155-2.198)$ & $1.680(1.207-2.338)$ \\
\hline Aged $\geq 35$ years & 1296 & $264(20.4)$ & & \\
\hline Seldom coffee drinkers & 348 & $62(17.8)$ & 1.000 & 1.000 \\
\hline Light coffee drinkers (< 1 cup/day) & 212 & $46(21.7)$ & 0.973(0.688-1.376) & 1.278(0.834-1.958) \\
\hline Moderate coffee drinkers (1 cup/day) & 455 & $101(22.2)$ & 1.119(0.847-1.479) & $1.316(0.925-1.872)$ \\
\hline Heavy coffee drinkers ( $\geq 2$ cups/day) & 281 & 55(19.6) & $1.594(1.155-2.198)$ & $1.123(0.750-1.679)$ \\
\hline
\end{tabular}

adjusted for age, body mass index, systolic blood pressure, cigarette smoking and alcohol consumption behavior, previous and current physical activity levels, stress levels, history of depression, presence of antenatal depressive symptoms during the first trimester, type of emesis, parity, and the number of livebirths, stillbirths, miscarriages, and abortions

increased risk of poor fetal and maternal outcomes, and perinatal mortality was observed to be more than twice as frequent in women who experienced bleeding in early pregnancy in the meta-analysis than in those who did not [12]. First trimester bleeding could indicate an underlying placental dysfunction, which may be related to later pregnancy complications [12]. Therefore, thorough prevention and management with healthy behavior from preconception to early pregnancy may help to prevent future fetal mortalities and morbidities. However, information on risk factors for bleeding in early pregnancy in the first trimester is insufficient and it is still unclear whether specific

Table 3 Association between coffee consumption frequency and the risk of bleeding in early pregnancy according to BMI ( $\mathrm{n}=$ 3510)

\begin{tabular}{|c|c|c|c|c|}
\hline$\overline{\mathrm{BMI}}$ & Total No. & No. (\%) & Unadjusted OR (95\% Cl) & Adjusted OR $(95 \% \mathrm{Cl})^{2}$ \\
\hline Underweight, $<18.5 \mathrm{~kg} / \mathrm{m}^{2}$ & 373 & $80(21.4)$ & & \\
\hline Seldom coffee drinkers & 155 & $33(21.3)$ & 1.000 & 1.000 \\
\hline Light coffee drinkers (<1 cup/day) & 52 & $11(21.2)$ & $0.992(0.460-2.139)$ & $0.780(0.331-1.837)$ \\
\hline Moderate coffee drinkers (1 cup/day) & 116 & $26(22.4)$ & $1.068(0.597-1.911)$ & $1.213(0.650-2.265)$ \\
\hline Heavy coffee drinkers ( $\geq 2$ cups/day) & 50 & 10(20.0) & $0.924(0.418-2.042)$ & $0.990(0.414-2.367)$ \\
\hline Normal, $18.5-24.9 \mathrm{~kg} / \mathrm{m}^{2}$ & 2683 & 463(17.3) & & \\
\hline Seldom coffee drinkers & 811 & 119(14.7) & 1.000 & 1.000 \\
\hline Light coffee drinkers (< 1 cup/day) & 460 & $80(17.4)$ & $1.224(0.898-1.669)$ & $1.249(0.912-1.712)$ \\
\hline Moderate coffee drinkers (1 cup/day) & 929 & 168(18.1) & 1.284(0.993-1.659) & 1.314(1.012-1.706) \\
\hline Heavy coffee drinkers ( $\geq 2$ cups/day) & 483 & 96(19.9) & $1.442(1.073-1.940)$ & $1.389(1.025-1.884)$ \\
\hline Overweight + Obese, $\geq 25.0 \mathrm{~kg} / \mathrm{m}^{2}$ & 454 & $93(20.5)$ & & \\
\hline Seldom coffee drinkers & 111 & 21(18.9) & 1.000 & 1.000 \\
\hline Light coffee drinkers (<1 cup/day) & 83 & $12(14.5)$ & $0.724(0.334-1.571)$ & $0.699(0.315-1.551)$ \\
\hline Moderate coffee drinkers (1 cup/day) & 157 & $32(20.4)$ & $1.097(0.594-2.026)$ & $1.059(0.554-2.025)$ \\
\hline Heavy coffee drinkers ( $\geq 2$ cups/day) & 103 & $28(27.2)$ & $1.600(0.841-3.045)$ & $1.574(0.801-3.093)$ \\
\hline
\end{tabular}

adjusted for age, body mass index, systolic blood pressure, cigarette smoking and alcohol consumption behavior, previous and current physical activity levels, stress levels, history of depression, presence of antenatal depressive symptoms during the first trimester, type of emesis, parity, and the number of livebirths, stillbirths, miscarriages, and abortions 


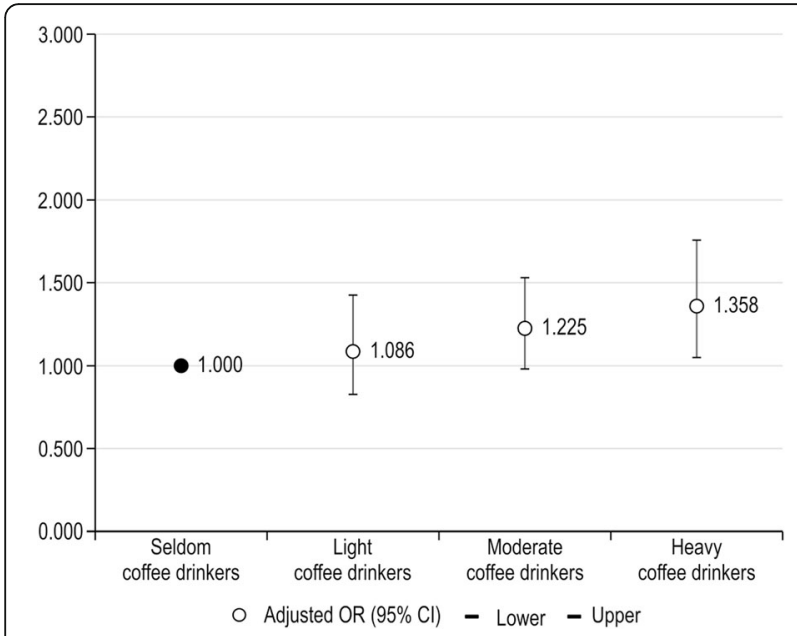

Fig. 2 Adjusted odds ratios for the risk of bleeding in early pregnancy according to coffee consumption

effects of caffeine is an independent risk factor for bleeding in early pregnancy $[12,18-21]$.

Coffee consumption is one possible risk factor for bleeding in early pregnancy in the first trimester. Even though the market for caffeinated beverages has increased in the past decades, coffee remains the most frequently consumed caffeinated beverage [1, 7]. A standard cup of coffee is generally expected to provide $100 \mathrm{mg}$ of caffeine; however, this varies according to portion size, brewing method, and brand [1-3, 6, 7, 22]. Although other beverages have some caffeine content (one cup of tea, $64.0 \mathrm{mg}$ of caffeine; $12 \mathrm{oz}$. of coke, $46.0 \mathrm{mg}$ of caffeine; one cup of hot chocolate, $16.0 \mathrm{mg}$ of caffeine; and caffeinated soda, $46.0 \mathrm{mg}$ of caffeine), these caffeinated beverages do not significantly affect daily caffeine consumption among Koreans $[7,23]$. Nisenblat et al. reported that caffeine intake is not associated with an increased risk of bleeding in early pregnancy, with the possible exception of very high levels of caffeine intake [22]. However, caffeine and its metabolites easily cross the placenta and may be present in considerable quantities in the amniotic fluid and fetal blood $[8,24]$. Moreover, the fetus metabolizes caffeine very slowly, and even extremely small amounts of maternal caffeine intake could lead to long-term fetal caffeine exposure $[22,24]$. Experimental and human studies have shown that caffeine exposure induces angiotensin II by stimulating the generation of reactive oxygen species, which ultimately inhibit angiogenesis and negatively affect the developing embryo [25]. In addition, caffeine consumption could increase the generation of circulating catecholamines, which could cause uteroplacental vasoconstriction, leading to fetal hypoxia [22, 26, 27]. Moreover, although a threshold for the adverse effects of caffeine on pregnant women was not well established, a few studies showed that high levels of caffeine intake could have adverse effects, such as miscarriage, fetal growth restriction, and long-term behavioral effects in offspring $[9,11,16,22,23,28,29]$.

Recently, some epidemiologic studies have found a significant association between a caffeine intake of $300 \mathrm{mg}$ or more/day and the risk of early pregnancy loss [23, 30,31]. Consistent with previous reports, in the present study, we found that pregnant women who were heavy coffee drinkers had a significantly higher risk of bleeding in early pregnancy. In a Chinese prospective study, caffeine intake before pregnancy was not found to increase the risk of early pregnancy loss, but caffeine intake of more than 300 $\mathrm{mg} /$ day during the first trimester appeared to significantly increase this risk [23]. A UK case-control study showed that caffeine consumption of more than $300 \mathrm{mg} /$ day during pregnancy approximately doubles the risk of miscarriage, and this effect is driven by coffee consumption [30]. Similarly, a study found that the adjusted risk of early pregnancy loss among Danish women who consumed more than $375 \mathrm{mg}$ of caffeine/day was 2.21 [31].

A meta-analysis found that the risk of pregnancy loss increased by $3 \%$ for every increase in coffee consumption of two cups/day [28]. Hence, most women try to reduce their caffeine intake considerably during pregnancy, especially from the time they start preparing for pregnancy to the first trimester $[9,29]$. The current guidelines of the World Health Organization recommend a caffeine intake below $300 \mathrm{mg} /$ day, whereas the American College of Obstetricians and Gynecologists recommend a maximum caffeine intake of $200 \mathrm{mg} /$ day [32, 33]. Different recommendations in guidelines can lead to confusion in preparing for pregnancy or during pregnancy. Moreover, knowing the exact caffeine content is difficult, because the amount varies depending on the serving size of the coffee.

The present study has some limitations that should be noted. The main limitation of the present study relates to the inaccurate assessment of the coffee consumption pattern, because the caffeine consumed in a "cup" of coffee varies according to portion size, brewing method, and brand type. Despite the huge popularity of decaffeinated coffee, we could not examine the consumption of decaffeinated coffee, especially in pregnant women. In future studies, objective measurements, combining caffeine exposure biomarkers from blood, urine, and saliva with 24-h dietary recall measurements, should be used to assess precise coffee consumption. Second, recall bias due to the retrospective assessment of caffeine consumption should be considered. However, since we examined coffee consumption before the onset of bleeding in early pregnancy, the impact of recall bias may have reduced. Third, coffee consumption patterns before pregnancy at a single time point may not reflect chronic exposure over the years, because women who prepare to conceive tend to maintain healthy eating habits. To address this concern in future studies, we should measure coffee consumption before pregnancy and evaluate the reliability of 
the FFQ. Finally, although we controlled for several potential confounders in our analysis, residual confounding by the effects of diet or other lifestyle factors may have been present. Additionally, a causal relationship between coffee consumption and bleeding in early pregnancy could not be assessed due to the observational design of this study.

\section{Conclusions}

Our results revealed a higher risk of bleeding in early pregnancy among those with heavy coffee consumption before pregnancy. Considering that coffee consumption is a potentially modifiable risk factor, our results indicate that caffeine intake before conception and during pregnancy should be reduced. Moreover, our study provides potentially useful information that can be used to address the need for nutritional interventions for healthy coffee drinking among pregnant women in Korea. Accordingly, it is necessary to recommend pregnant women to limit the amount of caffeine intake per day. However, further prospective studies are needed to confirm our findings and establish the causal associations between the potential negative effects of coffee consumption and the risk of bleeding in early pregnancy.

\section{Supplementary information}

Supplementary information accompanies this paper at https://doi.org/10. 1186/s12884-020-2798-1.

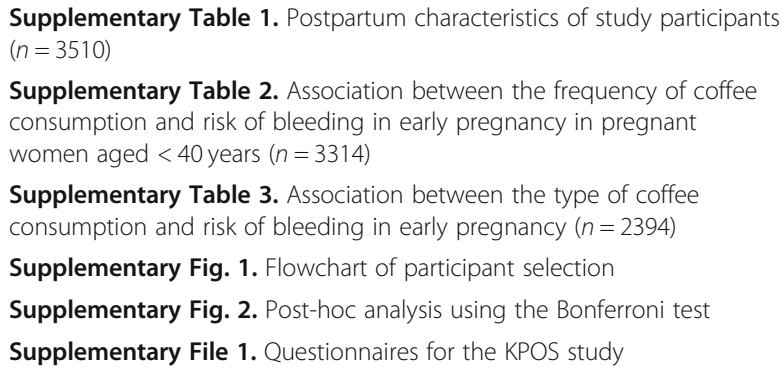

\section{Abbreviations}

Cl: Confidence intervals; IPAQ: International Physical Activity Questionnaire; IRB: Institutional Review Board; KPOS: Korean Pregnancy Outcome Study; OR: Odds ratios

\section{Acknowledgements}

We thank all the staff of the Division of Maternal Fetal Medicine in Cheil General Hospital and CHA Hospital who were involved in the conduction of the KPOS research.

\section{Authors' contributions}

$\mathrm{H}$-YP designed the study and reviewed the manuscript critically. $\mathrm{HC}$ analyzed and interpreted the data and contributed to the drafting of the manuscript. SK managed the data and provided clinical outputs. All authors read and approved the final version of the manuscript for submission.

\section{Funding}

This research was supported by the National Institute of Health and Korea Centers for Disease Control and Prevention (Grant No: 2018-NG001-00). The funding body was not involved in the design of the study, collection and analysis of data, and publication.

\section{Availability of data and material}

The KPOS is being conducted mainly at the Cheil General Hospital \& Women's Healthcare Center and CHA Gangnam Medical Center, where the staff are responsible for the collection, management, and distribution of data. All data are stored electronically in an anonymous format and are currently only available to KPOS researchers; however, data analysis collaborations may be possible through specific research proposals. Further information can be requested by e-mailing the principal investigator (hmryu2012@naver.com).

\section{Ethics approval and consent to participate}

All procedures were approved by the Institutional Review Boards (IRB) of Cheil General Hospital (IRB number: CGH-IRB-2013-10) and CHA University Gangnam CHA Hospital IRB (IRB number: 2013-14-KNC13-018), separately. All participants provided written informed consent prior to participation, and it was clearly explained to all participants that they were free to withdraw from any part of the study at any point in time.

\section{Consent for publication}

Not applicable.

\section{Competing interests}

The authors declare that they have no conflict of interest.

\section{Author details}

${ }^{1}$ Department of Epidemiology and Health Index, Center for Genome Science, Korea National Institute of Health, Korea Centers for Disease Control \& Prevention, Cheongju, Republic of Korea. ${ }^{2}$ Center for Genome Science, Korea National Institute of Health, Korea Centers for Disease Control \& Prevention, Cheongju, Republic of Korea.

Received: 12 June 2019 Accepted: 7 February 2020

Published online: 21 February 2020

\section{References}

1. Mitchell DC, Knight CA, Hockenberry J, Teplansky R, Hartman TJ. Beverage caffeine intakes in the US. Food Chem Toxicol. 2014:63:136-42.

2. Verster JC, Koenig J. Caffeine intake and its sources: a review of national representative studies. Crit Rev Food Sci Nutr. 2018;58:1250-9.

3. United States Department of Agriculture and Foreign Agricultural Service. South Korea: Coffee Market Brief Update. 2016. Available from: https://www. fas.usda.gov/data/south-korea-coffee-market-brief-update

4. Je Y, Jeong S, Park T. Coffee consumption patterns in Korean adults: the Korean National Health and nutrition examination survey (2001-2011). Asia Pac J Clin Nutr. 2014;23:691-702.

5. Ludwig IA, Clifford MN, Lean ME, Ashihara H, Crozier A. Coffee: biochemistry and potential impact on health. Food Funct. 2014;5:1695-717.

6. Heckman MA, Weil J. Gonzalez de Mejia E: caffeine (1, 3, 7trimethylxanthine) in foods: a comprehensive review on consumption, functionality, safety, and regulatory matters. J Food Sci. 2010;75:R77-87.

7. Lim HS, Hwang JY, Choi JC, Kim M. Assessment of caffeine intake in the Korean population. Food Addit Contam Part A Chem Anal Control Expo Risk Assess. 2015:32:1786-98.

8. Sajadi-Ernazarova KR, Hamilton RJ. Caffeine, Withdrawal. [Updated 2019 Jul 30]. In: StatPearls [internet]. Treasure Island (FL): StatPearls Publishing. 2019. Available from: https://www.ncbi.nlm.nih.gov/books/NBK430790/.

9. CARE Study Group. Maternal caffeine intake during pregnancy and risk of fetal growth restriction: a large prospective observational study. BMJ. 2008; 337:a2332.

10. Jouppila P. Clinical consequences after ultrasonic diagnosis of intrauterine hematoma in threatened abortion. J Clin Ultrasound. 1985;13:107-11.

11. Weng X, Odouli R, Li DK. Maternal caffeine consumption during pregnancy and the risk of miscarriage: a prospective cohort study. Am J Obstet Gynecol. 2008:198:279.e1-8.

12. Saraswat L, Bhattacharya S, Maheshwari A, Bhattacharya S. Maternal and perinatal outcome in women with threatened miscarriage in the first trimester: a systematic review. BJOG. 2010;117:245-57.

13. World Health Organization (WHO). International Association for the Study of Obesity (IASO) and International Obesity Task Force (IOTF). The Asia-Pacific Perspective: Redefining Obesity and its Treatment. World Health Organization. Geneva: Academic; 2000. p. 378-420. 
14. Cox JL, Holden JM, Sagovsky R. Detection of postnatal depression: development of the 10-item Edinburgh postnatal depression scale. Br J Psychiatry. 1987;150:782-6.

15. Kim YK, Hur JW, Kim KH, Oh KS, Shin YC. Clinical application of Korean version of Edinburgh postnatal depression scale. Psychiatry Clin Neurosci. 2008:47:36-44

16. Johns J, Muttukrishna S, Lygnos M, Groome N, Jauniaux E. Maternal serum hormone concentrations for prediction of adverse outcome in threatened miscarriage. Reprod BioMed Online. 2007;15:413-21.

17. Woodward PJ, Kennedy A, Sohaey R. Diagnostic imaging: obstetrics. $3^{\text {rd }}$ ed Elsevier Health Sciences; 2016.

18. Kanmaz AG, Inan AH, Beyan E, Budak A. The effects of threatened abortions on pregnancy outcomes. Ginekol Pol. 2019;90:195-200.

19. Farrell $T$, Owen $P$. The significance of extrachorionic membrane separation in threatened miscarriage. Br J Obstet Gynaecol. 1996;103:926-8.

20. Dadkhah F, Kashanian M, Eliasi G. A comparison between the pregnancy outcome in women both with or without threatened abortion. Early Hum Dev. 2010;86:193-6.

21. Van Oppenraaij R, Jauniaux E, Christiansen O, Horcajadas J, Farquharson R, Exalto N. Predicting adverse obstetric outcome after early pregnancy events and complications: a review. Hum Reprod Update. 2009;15:409-21.

22. Nisenblat $V$, Norman RJ. The effects of caffeine on reproductive outcomes in women. Retrieved October. 2016;16.

23. Wen W, Shu XO, Jacobs DR Jr, Brown JE. The associations of maternal caffeine consumption and nausea with spontaneous abortion. Epidemiology. 2001:12:38-42.

24. Berger A. Effects of caffeine consumption on pregnancy outcome. A Rev J Reprod Med. 1988:33:945-56.

25. Ma Z, Wang G, Wh L, Cheng X, Chuai M, KKH L, Yang X. Investigating the effect of excess caffeine exposure on placental angiogenesis using chicken 'functional' placental blood vessel network. J Appl Toxicol. 2016;36:285-95.

26. Kirkinen P, Jouppila P, Koivula A, Vuori J, Puukka M. The effect of caffeine on placental and fetal blood flow in human pregnancy. Am J Obstet Gynecol. 1983;147:939-42.

27. Tsubouchi H, Shimoya K, Hayashi S, Toda M, Morimoto K, Murata Y. Effect of coffee intake on blood flow and maternal stress during the third trimester of pregnancy. Int J Gynecol Obstet. 2006;92:19-22.

28. Li J, Zhao H, Song JM, Zhang J, Tang YL, Xin CM. A meta-analysis of risk of pregnancy loss and caffeine and coffee consumption during pregnancy. Int J Gynaecol Obstet. 2015;130:116-22.

29. Peck JD, Leviton A, Cowan LD. A review of the epidemiologic evidence concerning the reproductive health effects of caffeine consumption: a 2000-2009 update. Food Chem Toxicol. 2010;48:2549-76.

30. Giannelli M, Doyle P, Roman E, Pelerin M, Hermon C. The effect of caffeine consumption and nausea on the risk of miscarriage. Paediatr Perinat Epidemiol. 2003;17:316-23.

31. Rasch V. Cigarette, alcohol, and caffeine consumption: risk factors for spontaneous abortion. Acta Obstet Gynecol Scand. 2003;82:182-8.

32. American College of Obstetricians and Gynecologists. Moderate caffeine consumption during pregnancy. Committee Opinion No. 462. Obstet Gynecol. 2010;116:467-8

33. World Health Organization. The world health report 2002: reducing risks, promoting healthy life. WHO press kit; 2002.

\section{Publisher's Note}

Springer Nature remains neutral with regard to jurisdictional claims in published maps and institutional affiliations.

Ready to submit your research? Choose BMC and benefit from:

- fast, convenient online submission

- thorough peer review by experienced researchers in your field

- rapid publication on acceptance

- support for research data, including large and complex data types

- gold Open Access which fosters wider collaboration and increased citations

- maximum visibility for your research: over $100 \mathrm{M}$ website views per year

At $\mathrm{BMC}$, research is always in progress.

Learn more biomedcentral.com/submissions 